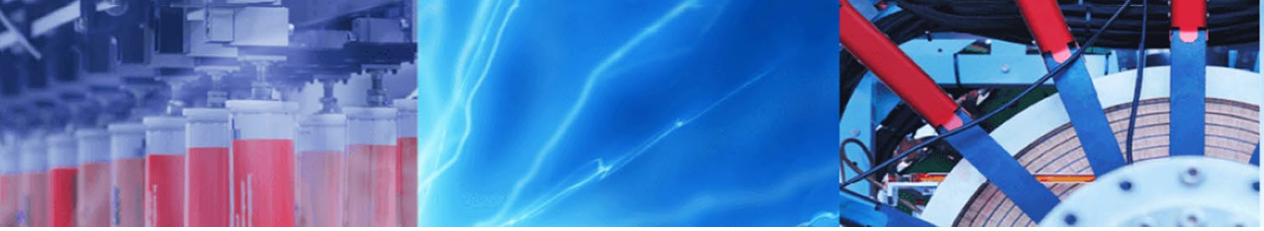

Research Article

\title{
Prognosis of access to biomass residue resources in rural areas to provide energy for villagers
}

\author{
Hanif Esmaeili ${ }^{1}$ (D) $\cdot$ Mehran Farhadi $^{1}$
}

Received: 10 September 2019 / Accepted: 6 February 2020 / Published online: 18 February 2020

(c) Springer Nature Switzerland AG 2020

\begin{abstract}
The potential evaluation of available biowaste was carried out for 95 villages of Gorgan in this study. The resources studied were wastes resulting from agricultural activities, including farming, horticulture, and livestock, as well as rural waste and wastewater. A coefficient was used to access the resources by filling a questionnaire, interviewing with experts and the use of the fuzzy analytic hierarchy process in order to have a theoretical estimation of resources closer to reality. This coefficient was determined based on the five factors including the suitability of warehousing, ease of transportation, quality of collection mechanism, access to production areas and no collection losses. Then, the information was geo-referenced in geographic information system. It was found that the total potential of the villages was 1,191,022 GJ, most of which were related to agricultural $(9,87,986 \mathrm{GJ})$ and horticulture $(94,416 \mathrm{GJ})$ waste, respectively. Regarding the per capita waste generation and the limiting factor of distance from natural gas transmission lines, southern parts of the province could be among the priority villages for biofuels development.
\end{abstract}

Keywords Biomass $\cdot$ Biowaste $\cdot$ Residual biomass $\cdot$ Bioenergy $\cdot$ Rural residue $\cdot$ Potentiometric $\cdot$ FAHP

\section{Introduction}

Bioenergy production has received a considerable attention during recent years. Consequently, some concerns have been raised regarding this rapid growth which include the change in ecosystem, an increase in food prices and resource constraints. Utilizing the residual biomass is an approach to decrease the negative influences of biomass energy production [1]. All liquid and solid wastes which are indirectly or directly the outcome of human activities are called residual biomass and, in the matter of production, are considered as waste. These residuals are produced in a variety of areas, including industrial and agricultural production units, food stores, commercial and residential areas and other different places [2]. Regarding the economic and environmental aspects, residual biomass is available. Nevertheless, evaluation of its potential applications when added to other supply chains is necessary. The lack of concentration, which leads to a difficult collection and transportation, is one of the major limitations of the biomass resources in terms of producing energy from these materials. Hence, an accurate estimation of their potential and utilization for producing energy in susceptible areas are necessary [3]. Furthermore, it is critical to manage the biomass resources sustainably, and although they are abundant and geographically distributed widely, they should be utilized with permission.

The purpose of the present study is to estimate the residual biomass resources' potential for renewable energy production in Gorgan county, Iran. The energy resources in this region for the residential sector are fossil fuels, including liquefied petroleum gas, gasoline, natural gas and kerosene. The natural gas is provided for the residents

Hanif Esmaeili, hanifsmaili@gmail.com | ${ }^{1}$ Department of Agricultural Mechanization, Science and Research Branch, Islamic Azad University, Tehran, Iran. 
by the national pipeline, and other sources of energy are hard to provide.

In this respect, after determination of the magnitude of residual biomass, qualitative criteria were identified for each resource access. The paired comparison method and the fuzzy analytical hierarchy process (FAHP) method were used to determine the weight of each factor which were considered as the coefficients of the corresponding resource. Lastly, the geographical information system (GIS) was used to analyze the waste resources, and rural areas' status was determined regarding the waste materials' potential and accessibility to the regular energy carriers of the region.

\subsection{Case study}

Gorgan, in the south part of Golestan, is located in the southeast of the Caspian Sea and northeastern of Iran. There are three areas in this region, including foothills, sub-humid and plain. The north and south of the city have semi-humid and mountainous climate, respectively. Arable land in Gorgan is about $63,157 \mathrm{~km}^{2}$ which is approximately $39 \%$ of the total land areas. Figure 1 shows the dispersion map of the villages and the corresponding lands. The rural population is 118,478 people which accounts for about $23 \%$ of the total population of Gorgan. The dispersion map for the rural population of the region is presented in Fig. $2[4,5]$. In the present study, statistical average data for 95 villages, which were provided in 2018, were used

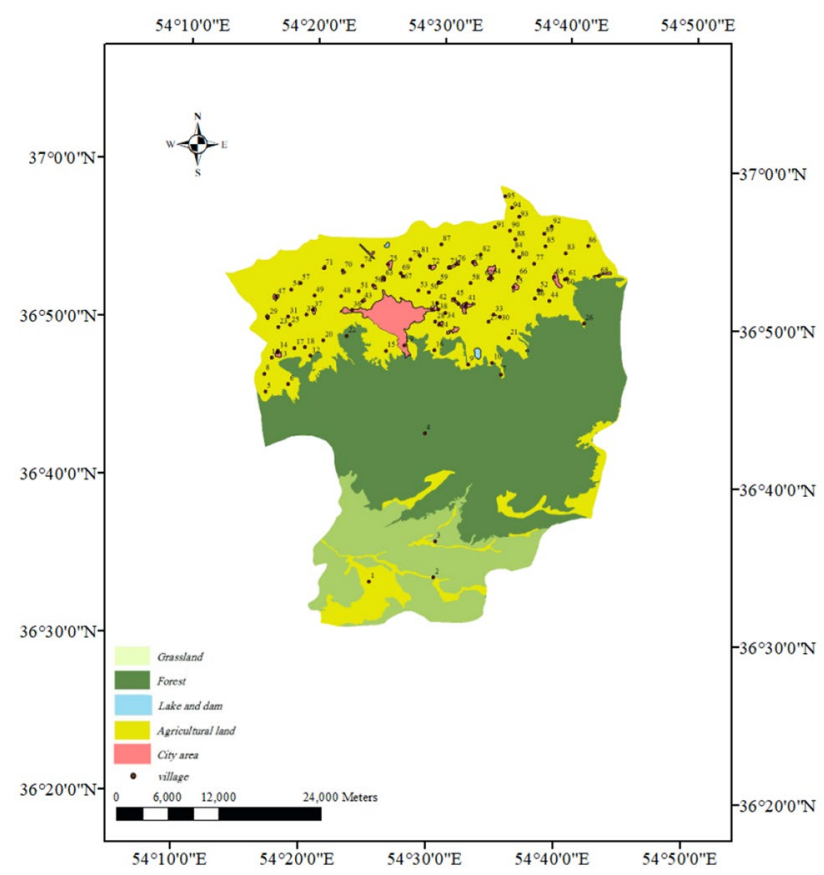

Fig. 1 Land use in study area

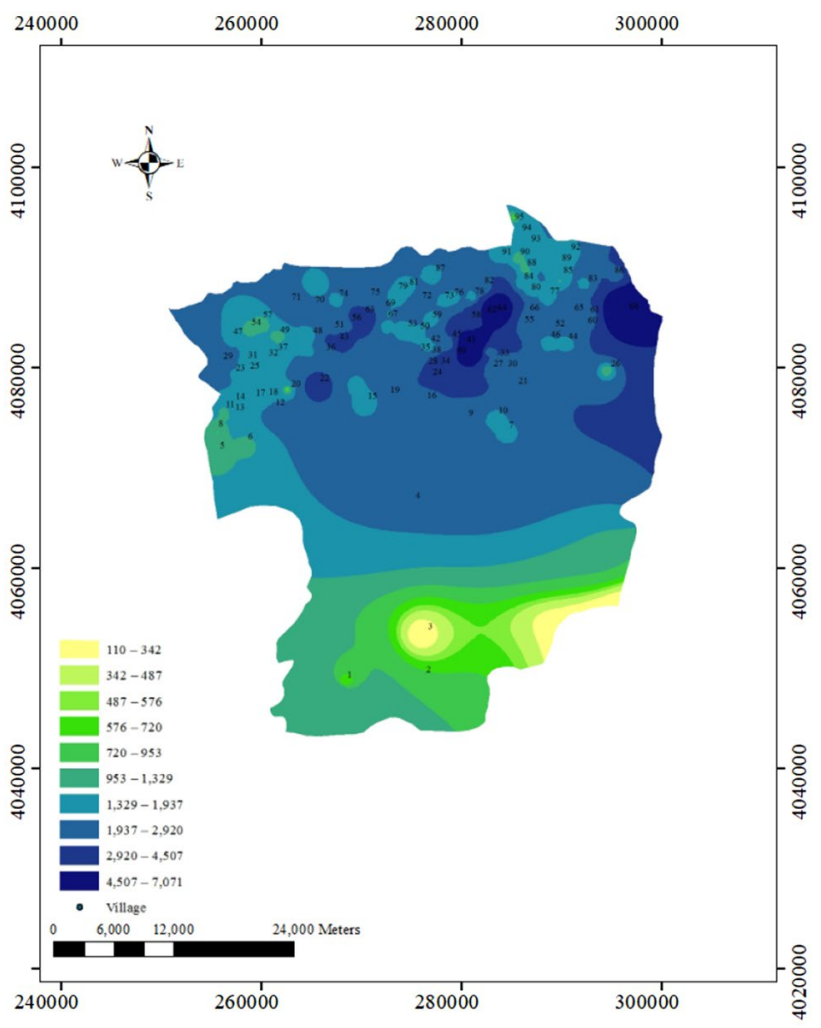

Fig. 2 Population dispersion (People)

as the study regions for which the rural biowaste potential is estimated. Just like many other cities in Iran, Gorgan uses natural gas transmission pipelines to provide thermal energy to the rural and urban areas. Having 19.6 million Iranian households who use natural gas service line from the late 2017, this is the major residential energy supply in Iran [6]. Since many villages are located far from the major pipeline, they do not have access to the fuel. The energy resources for these rural areas are usually being provided by old methods which have problems regarding the health issues and energy supply.

\section{Methodology}

The residual biomass resources are categorized based on the purpose of the present study, as listed in Table 1. Because of difficulty in collecting the waste and the low production and proportion of the wastes, other agricultural products and other residual biomass sources are neglected. Agricultural and rural waste data were provided and classified from the Gorgan Annual Census Data since 2018. Data were gathered through interviews with the Rural Council for villages with no available information.

First, accessibility to the resources was determined so the estimated and actual values will be more consistent. 
Table 1 Biomass classification in villages of Gorgan

\begin{tabular}{ll}
\hline Biomass resources & Description \\
\hline Farming & $\begin{array}{l}\text { Grain (wheat, barley, soybean, rice) } \\
\text { vegetable (potato and tomato) residue }\end{array}$ \\
Horticulture & $\begin{array}{l}\text { Fruit residue } \\
\text { Tree residue }\end{array}$ \\
Rural Waste & Household \\
Wastewater & Household \\
Livestock & Cow and calf \\
& Sheep, ewe and goat \\
& Horse \\
& Chicken
\end{tabular}

The access coefficients were regarded as a factor for the utilization of resources. This method was determined based on the principal and technology of organic waste utilization [2] and the status of the residual biomass accessibility, cultivation, crop type, production dispersion, mechanization of operation and other similar factors. Five qualitative parameters, including ease of

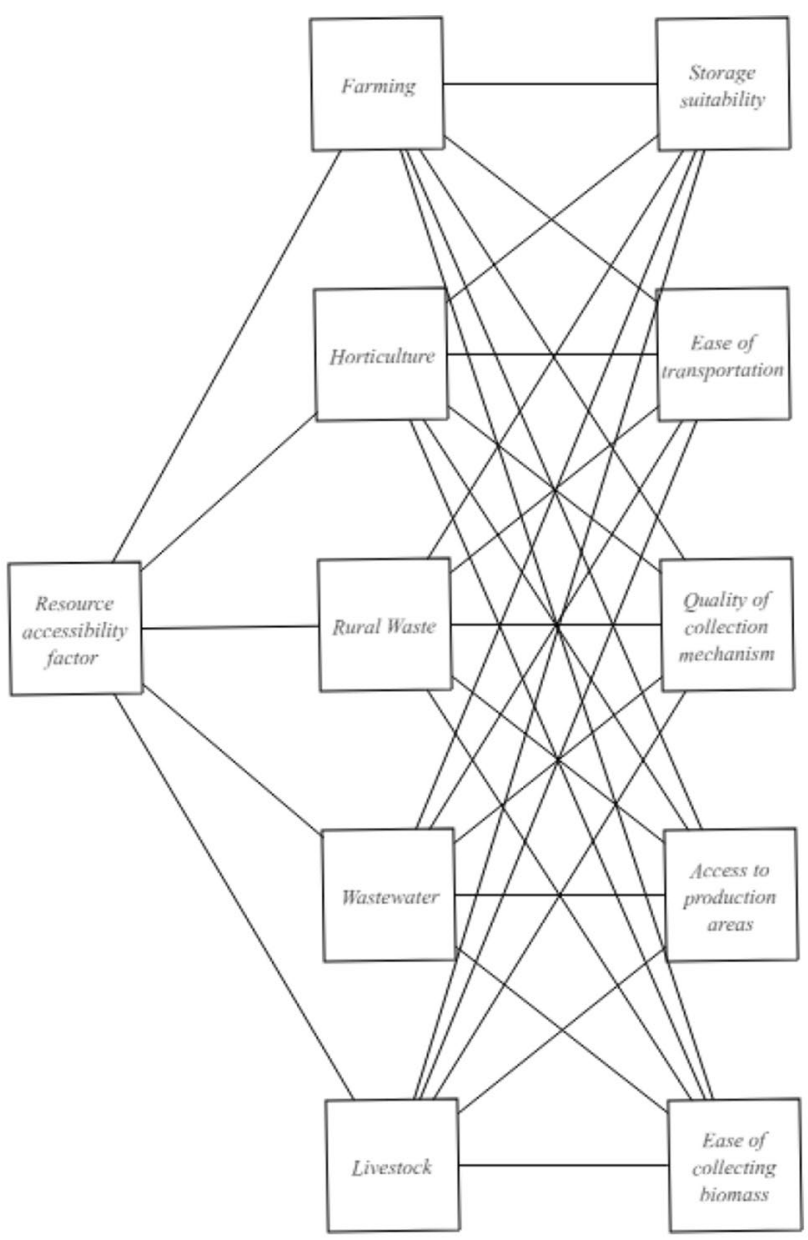

Fig. 3 Tree diagram of resource accessibility

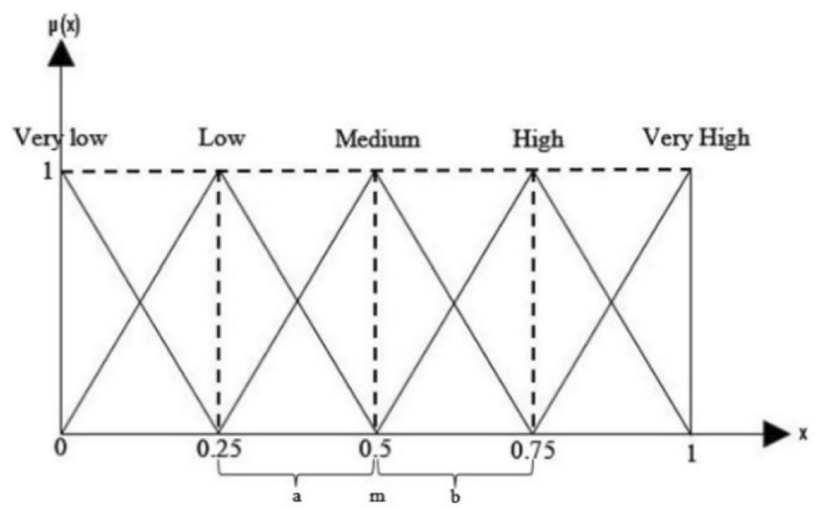

Fig. 4 The fuzzy triangular numbers equal to qualitative number

Table 2 Linguistic variable and their fuzzy equivalent

\begin{tabular}{lll}
\hline & $\begin{array}{l}\text { The triangulated fuzzy } \\
\text { number }\end{array}$ & $\begin{array}{l}\text { Quan- } \\
\text { titative } \\
\text { number }\end{array}$ \\
\hline Very low & $(0,0,0.25)$ & 0.1 \\
Low & $(0.25,0.25,0.25)$ & 0.3 \\
Medium & $(0.5,0.25,0.25)$ & 0.5 \\
High & $(0.75,0.25,0.25)$ & 0.7 \\
Very high & $(1,0.25,0)$ & 0.9 \\
\hline
\end{tabular}

Table 3 The fundamental scale of AHP

\begin{tabular}{ll}
\hline Definition & Score \\
\hline Equal importance & 1 \\
Weak importance of one over another & 3 \\
Essential or strong importance & 5 \\
Very strong and demonstrated & 7 \\
Absolute importance & 9 \\
Intermediate values between adjacent scale values & $2,4,6,8$ \\
\hline
\end{tabular}

biomass collection, ease of transportation, storage suitability, access to production areas and quality of collection mechanism, were chosen for determination of the factor of accessibility to the resources by interviewing nine researchers and experts. The criteria's weights were determined by the fuzzy analytical hierarchy process (FAHP) method. Figure 3 presents the tree diagram of the network analysis process.

Based on the aforementioned five parameters, 15 experts who were selected by Snowball sampling technique designed and weighted the pair comparison questionnaire. The snowball sampling technique is a consecutive purposive sampling method which is applicable in 
Fig. 5 Graphical abstract of the study methodology

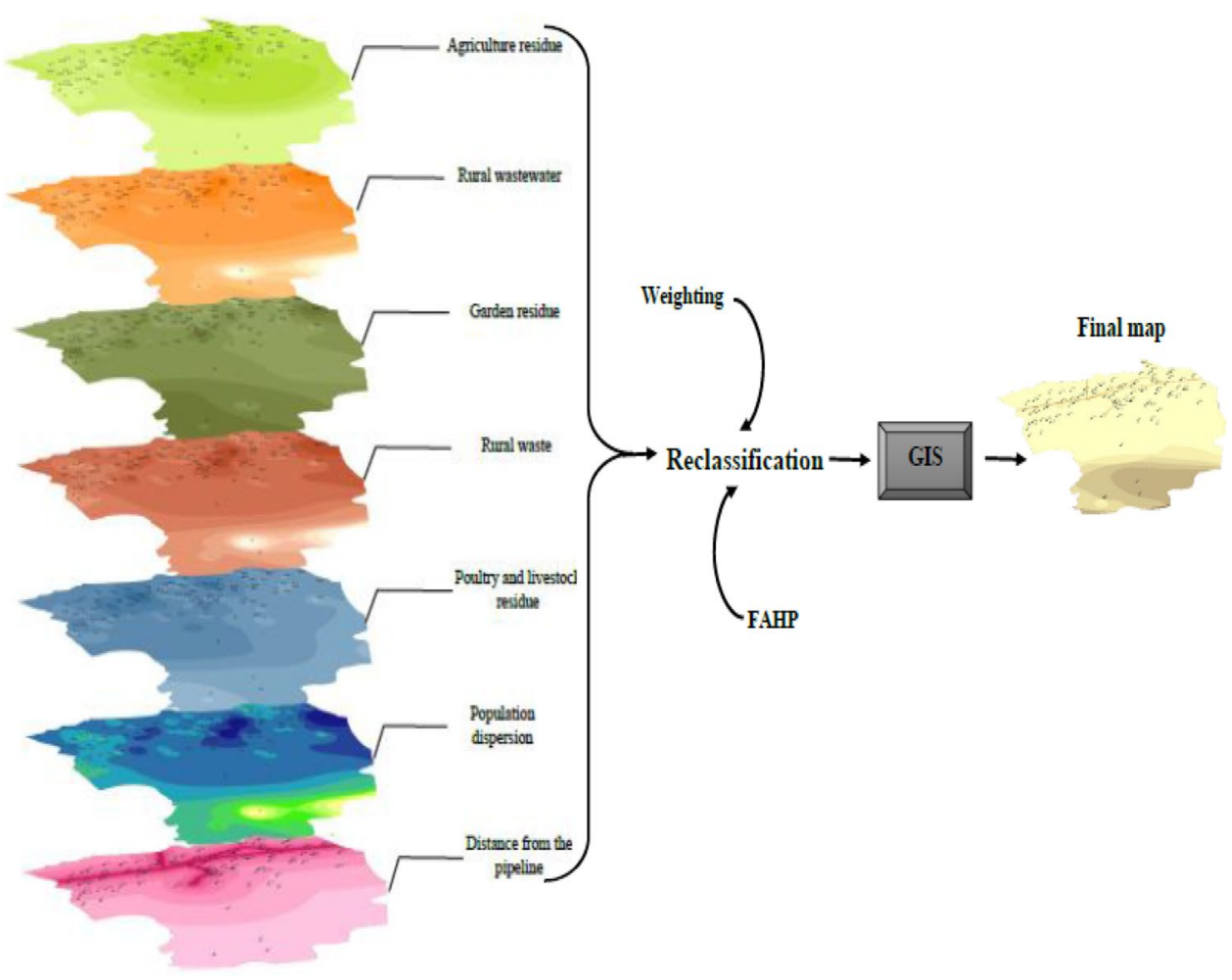

Table 4 Scoring table for the accessibility coefficient (weighted values)

\begin{tabular}{lllllll}
\hline & $\begin{array}{l}\text { Storage } \\
\text { suitability }\end{array}$ & $\begin{array}{l}\text { Ease of } \\
\text { transporta- } \\
\text { tion }\end{array}$ & $\begin{array}{l}\text { Quality of collec- } \\
\text { tion mechanism }\end{array}$ & $\begin{array}{l}\text { Access to pro- } \\
\text { duction areas }\end{array}$ & $\begin{array}{l}\text { Ease of collecting biomass } \\
\text { Impor- } \\
\text { tance } \\
\text { degree }\end{array}$ \\
\hline Storage suitability & 1 & 0.5 & 0.33 & 0.25 & 0.33 & 0.072 \\
Ease of transportation & 2 & 1 & 0.5 & 0.25 & 0.5 & 0.111 \\
Quality of collection mechanism & 3 & 2 & 1 & 0.5 & 2 & 2 \\
Access to production areas & 4 & 4 & 2 & 0.5 & 1 & 0.244 \\
Ease of collecting biomass & 3 & 2 & 0.5 & & Inconsistency $=0.02$ \\
\hline
\end{tabular}

Table 5 Quantitative values of qualitative criteria

\begin{tabular}{llllll}
\hline & $\begin{array}{l}\text { Storage suit- } \\
\text { ability }\end{array}$ & $\begin{array}{l}\text { Ease of trans- } \\
\text { portation }\end{array}$ & $\begin{array}{l}\text { Quality of collec- } \\
\text { tion mechanism }\end{array}$ & $\begin{array}{l}\text { Access to pro- } \\
\text { duction areas }\end{array}$ & $\begin{array}{l}\text { Ease of } \\
\text { collecting } \\
\text { biomass }\end{array}$ \\
\hline Farm & 0.7 & 0.5 & 0.9 & 0.3 & 0.5 \\
Horticulture & 0.7 & 0.5 & 0.3 & 0.5 & 0.7 \\
Rural Waste & 0.3 & 0.5 & 0.5 & 0.7 & 0.5 \\
Wastewater & 0.1 & 0.3 & 0.3 & 0.5 & 0.7 \\
Livestock & 0.3 & 0.3 & 0.5 & 0.9 & 0.7 \\
\hline
\end{tabular}

multi-criteria decision making where the researcher asks the expert, who provides data, to introduce other experts [7].
Triangular fuzzy number (TFN) method was used in the present study to evaluate the residual biomass source accessibility. This method was chosen because of the nature and number of the options. In this method, a 
Table 6 Weights of each factor for each of the sources

\begin{tabular}{|c|c|c|c|c|}
\hline Accessibility factor & $\begin{array}{l}\text { Importance } \\
\text { degree }\end{array}$ & Resource & $\begin{array}{l}\text { Qualitative } \\
\text { criteria }\end{array}$ & Weight \\
\hline \multirow[t]{5}{*}{ Storage suitability } & 0.072 & Farm & 0.7 & 0.050 \\
\hline & & Horticulture & 0.7 & 0.050 \\
\hline & & Rural Waste & 0.3 & 0.022 \\
\hline & & Wastewater & 0.1 & 0.007 \\
\hline & & Livestock & 0.3 & 0.022 \\
\hline \multirow[t]{5}{*}{ Ease of transportation } & 0.111 & Farm & 0.5 & 0.056 \\
\hline & & Horticulture & 0.5 & 0.056 \\
\hline & & Rural Waste & 0.5 & 0.056 \\
\hline & & Wastewater & 0.3 & 0.033 \\
\hline & & Livestock & 0.3 & 0.033 \\
\hline \multirow[t]{5}{*}{ Quality of collection mechanism } & 0.244 & Farm & 0.7 & 0.171 \\
\hline & & Horticulture & 0.3 & 0.072 \\
\hline & & Rural Waste & 0.5 & 0.122 \\
\hline & & Wastewater & 0.3 & 0.072 \\
\hline & & Livestock & 0.5 & 0.122 \\
\hline \multirow[t]{5}{*}{ Access to production areas } & 0.388 & Farm & 0.3 & 0.116 \\
\hline & & Horticulture & 0.5 & 0.194 \\
\hline & & Rural Waste & 0.7 & 0.272 \\
\hline & & Wastewater & 0.5 & 0.194 \\
\hline & & Livestock & 0.9 & 0.349 \\
\hline \multirow[t]{5}{*}{ Ease of collecting biomass } & 0.184 & Farm & 0.5 & 0.092 \\
\hline & & Horticulture & 0.7 & 0.129 \\
\hline & & Rural Waste & 0.5 & 0.092 \\
\hline & & Wastewater & 0.7 & 0.129 \\
\hline & & Livestock & 0.7 & 0.129 \\
\hline
\end{tabular}

triangular fuzzy number with the form of $(m, a, b)$ represents a qualitative option, where $m, a$ and $b$ are the mean, left and right tolerances, respectively $[(0,0,0.25=$ very low), $(0.25,0.25,0.25=$ low $),(0.5,0.25,0.25=$ medium $)$, $(0.75,0.25,0.25=$ high $),(1,0.25,0=$ very high $)]$. The TFN corresponding to each one of the qualitative numbers is shown in Fig. 4.

The Chen-Hwang method is used to convert a triangular fuzzy number to a definite value [8]. Maximum and minimum functions as follows have to be defined firstly for converting normal fuzzy numbers to definite amounts:

$\mu \operatorname{Max}(x)= \begin{cases}x & 0 \leq x \leq 1 \\ 0 & \end{cases}$

$\mu \min (x)=\left\{\begin{array}{ll}1-x & 0 \leq x \leq 1 \\ 0\end{array}\right.$.

The maximum and minimum values create the right and left tolerances for the fuzzy number. These values are the membership degree of the fuzzy number $(\mu(x))$ at the intersection points where the right and left tolerances are shown as $\left(\mu_{\mathrm{L}}(x)\right)$ and $\left(\mu_{\mathrm{R}}(x)\right)$. Given the triangular fuzzy numbers $(m, a, b)$, the definite values of the left and right tolerance, and quantitative number, can be obtained from the following equations:

$\mu_{\mathrm{R}}(x)=1-\frac{1}{1+b}(1-m)$

$\mu_{\mathrm{L}}(x)=1-\frac{1}{1+a}(m)$

$\mu_{\mathrm{\top}}=\frac{m+\mathrm{b}}{2(1+\mathrm{b})}+\frac{m}{2(1+\mathrm{a})}$

where $\mu_{\mathrm{T}}$ is a number which is equal to the TFN shown by $m, a$ and $b . m$ is the average value, $a$ is left tolerance value, and $b$ is right tolerance value as listed in Table 2 .

The analysis hierarchy process (AHP) was selected by the expert choice software and used to obtain the weight of the sub-criteria and criteria. The pair-wise comparison matrix was used to measure the significance of each of the criteria compared to the others. Let $a_{i j}$ be the element lying in the $i$ th row and $j$ th column of the 
Table 7 Overall desirable accessibility of each source

\begin{tabular}{|c|c|c|}
\hline Resource & Accessibility factor & Weight \\
\hline \multirow[t]{5}{*}{ Farm } & Storage suitability & 0.050 \\
\hline & Ease of transportation & 0.056 \\
\hline & Quality of collection mechanism & 0.171 \\
\hline & Access to production areas & 0.116 \\
\hline & Ease of collecting biomass & 0.092 \\
\hline \multirow[t]{5}{*}{ Horticulture } & Storage suitability & 0.050 \\
\hline & Ease of transportation & 0.056 \\
\hline & Quality of collection mechanism & 0.072 \\
\hline & Access to production areas & 0.194 \\
\hline & Ease of collecting biomass & 0.129 \\
\hline \multirow[t]{5}{*}{ Rural waste } & Storage suitability & 0.022 \\
\hline & Ease of transportation & 0.056 \\
\hline & Quality of collection mechanism & 0.122 \\
\hline & Access to production areas & 0.272 \\
\hline & Ease of collecting biomass & 0.092 \\
\hline \multirow[t]{5}{*}{ Wastewater } & Storage suitability & 0.007 \\
\hline & Ease of transportation & 0.033 \\
\hline & Quality of collection mechanism & 0.072 \\
\hline & Access to production areas & 0.194 \\
\hline & Ease of collecting biomass & 0.129 \\
\hline \multirow[t]{5}{*}{ Livestock } & Storage suitability & 0.022 \\
\hline & Ease of transportation & 0.033 \\
\hline & Quality of collection mechanism & 0.122 \\
\hline & Access to production areas & 0.349 \\
\hline & Ease of collecting biomass & 0.129 \\
\hline
\end{tabular}

matrix, and the following formula is used to fill the lower diagonal:

$a_{j i}=\frac{1}{a_{i j}}$

Lastly, the relative and total weights were calculated for each factor and the access coefficient was determined for each resource. The scale range of 1-9 by Thomas Saaty was used to weight the factors, as listed in Table 3 [9].

Determination of the residual biomass potential was done based on its heating value for co-equilibrating the resources values. The instructions of Washington State University Biomass Inventory [10-12] and Bioenergy Assessment and University of Freiburg Biomass Energy Europe Project were used for estimation $[13,14]$. The agricultural and rural wastes were categorized into five classes, including household waste, farming and horticulture waste, wastewater, livestock and poultry manure and agricultural residue, after the data of 95 villages were collected for the region. Since they are the major crops of the region, barley, wheat, rice and rapeseed were considered for grain waste, while tomato and potato waste were considered for vegetable waste. Two categories of wastes were considered for horticulture products, including waste of the leaves and crop loses and wastes of the branches which correspond to the annual tree trimming. The products of this region include peach, pear, apple, olive, citrus, cherry and plum. The amount of horticulture and agricultural biomass is theoretically collected per year. This is done using Eqs. 7 and 8 in form of Mega joules per unit area where the higher heating value ( $\mathrm{HHV}$ ) is used to convert biomass into energy.

$\mathrm{EA}_{j}=\sum_{i=1}^{n}\left(\mathrm{CA}_{i \cdot j} \times \mathrm{AP}_{i \cdot j} \times \mathrm{Pt} R_{i \cdot j} \times \mathrm{Av}_{i \cdot j} \times \mathrm{HHV}_{i}\right)$

where $\mathrm{EA} j$ is the theoretical potential of farming residues at $j$ state from $n$ type of crops, (GJ/year); $C A i, j$ is the cultivated area of $i$ crop at $j$ state, hectares; $A P i, j$ is agricultural production of $i$ crop at $j$ state, tonne per hectare; PtRi $i j$ is the product to residue ratio of $i$ crop at $j$ state; $A v_{i . j}$ is the availability of residues for $i$ crop according to current harvesting system at $j$ state; $\mathrm{HHVi}$ is the higher heating value of $i$ crop, (GJ/tonne); $i$ is the type of crop.

$\mathrm{EW}_{j}=\sum_{i=1}^{n}\left(\mathrm{ATH}_{i \cdot j} \times \mathrm{Rr}_{i \cdot j} \times \mathrm{HP}_{i \cdot j} \times \mathrm{HHV}_{i}\right)$

where EW is the theoretical potential of stemwood residues at state $j$ from $n$ type of stemwood, (GJ/year); $\mathrm{ATH}_{i, j}$ is the annual timber harvest of $i$ crop at $j$ state, hectare; $R r$ is the residue ratio of $i$ crop at $j$ state, tonne/m $\mathrm{m}^{3} ; \mathrm{HP}_{i, j}$ is the harvest percentage of $i$ crop at $j$ state, (\%); $\mathrm{HHV}_{i}$ is the higher heating value of $i$ crop, (GJ/tonne).

Biogas, the main product of manure digestion, is used for energy exploitations. Therefore, in order to provide the energy potential, the amount of manure can be multiplied with the specific biogas yield and the energy content of biogas. The theoretical potential of energy production from animal and poultry manure is derived from Eq. 9.

$\mathrm{EM}_{j}=\sum_{i=1}^{n} \mathrm{NH}_{i \cdot j} \times \mathrm{MpH}_{i \cdot j} \times \mathrm{BY}_{i} \times \mathrm{BEC}_{i}$

where $\mathrm{EM} j$ is the theoretical potential of manure at $j$ state from $n$ type of livestock, (GJ/year); $\mathrm{NH}_{i, j}$ is the number of heads for the $i$ type of livestock at $j$ state, head; $\mathrm{MH}_{i, j}$ is the amount of manure for the $i$ type of livestock at $j$ state, tonne per head; $\mathrm{BY}_{i}$ is the biogas yields for the $i$ type of livestock manure, in cubic meters $\left(\mathrm{m}^{3}\right)$ per tonne; $\mathrm{BEC}_{i}$ is the energy content of gas produced from the $i$ type of livestock manure $\left(\mathrm{GJ} / \mathrm{m}^{3}\right)$; and $i$ is the type of livestock.

A straightforward approach to determine the theoretical and technical potential of biodegradable municipal solid waste (BMW) is based on thermal applications (like incineration). This method is described in Eq. 10. 
Table 8 Acronym table

\begin{tabular}{|c|c|}
\hline Acronym & Explanation \\
\hline AHP & Analytic hierarchy process \\
\hline AMSL & Above mean sea level \\
\hline $\mathrm{AP}_{i, j}$ & Agricultural production of $i$ crop at $j$ state \\
\hline ATH $_{i, j}$ & Annual timber harvest of $i$ crop at $j$ state \\
\hline $\mathrm{BEC}_{i}$ & Energy content of gas produced from the $i$ type of livestock manure \\
\hline BMW & Biodegradable municipal solid waste \\
\hline $\mathrm{BY}_{i}$ & Biogas yields for the $i$ type of livestock manure \\
\hline $\mathrm{CA}_{i, j}$ & Cultivated area of $i$ crop at $j$ state \\
\hline $\mathrm{EAj}$ & Theoretical potential of farming residues at $j$ state from $n$ type of crops \\
\hline $\mathrm{EB}_{x}$ & Biomass potential of biodegradable rural solid waste of village $x$ \\
\hline EMj & Theoretical potential of manure at $j$ state from $n$ type of livestock \\
\hline ESx & Theoretical biomass potential of sewage Gas of village $x$ \\
\hline EW & Theoretical potential of stemwood residues at state $j$ from $n$ type of stemwood \\
\hline FAHP & Fuzzy analytic hierarchy process \\
\hline GEC & Energy content of gas produced \\
\hline GIS & Geographic information system \\
\hline GJ & Gigajoule \\
\hline GY & Gas yield \\
\hline $\mathrm{HHV}$ & Higher heating value \\
\hline $\mathrm{HP}_{i, j}$ & Harvest percentage of $i$ crop at $j$ state \\
\hline IDW & Inverse distance weighting \\
\hline $\mathrm{MH}_{i, j}$ & Amount of manure for the $i$ type of livestock at $j$ state \\
\hline $\mathrm{NH}_{i, j}$ & The number of heads for the $i$ type of livestock at $j$ state \\
\hline $\mathrm{OC}_{x}$ & Organic content of rural solid waste \\
\hline $\mathrm{OM}$ & Organic dry matter of sewage sludge in rural sewage plants \\
\hline $\mathrm{PtR}_{i, j}$ & Product to residue ratio of $i$ crop at $j$ state \\
\hline$P_{x}$ & Population of village $x$ \\
\hline$R r$ & Residue ratio of $i$ crop at $j$ state \\
\hline $\mathrm{RWS}_{x}$ & Percentage of the population served by rural waste services \\
\hline $\mathrm{RW}_{x}$ & Rural waste production per capita of village $x$ \\
\hline $\mathrm{S}_{x}$ & Amount of sewage sludge treated in rural sewage of village $x$ \\
\hline TFN & Triangular fuzzy number \\
\hline
\end{tabular}

$\mathrm{EB}_{x}=\mathrm{RW}_{x} \times P_{x} \times \mathrm{RWS}_{x} \times \mathrm{OC}_{x} \times \mathrm{HHV}$

where EBx is the biomass potential of biodegradable rural solid waste of village $x$ (GJ/year); RWx is the rural waste production per capita of village $x$ (tonnes/person/year); $P_{x}$ is the population of village $x$ (persons); RWS $x$ is the percentage of the population served by rural waste services (\%); $\mathrm{OC}_{x}$ is the organic content of rural solid waste (dimensionless); $\mathrm{HHV}$ is the high heating value of biodegradable municipal solid waste (GJ/tonne); and $\times$ is the village.

Sewage sludge is produced during sewage treatment of wastewater. The obtained raw primary sludge needs to be further stabilized for the transportations. (Primary raw sludge is required to become more stable in order to be transported.) The treatment is done either anaerobically or aerobically. In the first case, the generated sewage gas is mainly composed of methane. Equation 11, theoretically, shows the calculation of rural wastewater. This equation is a function of biogas thermal energy produced from rural sewage.

$\mathrm{ES}_{x}=S_{x} \times \mathrm{OM} \times \mathrm{GY} \times \mathrm{GEC}$.

$\mathrm{ES}_{\mathrm{x}}$ is the theoretical biomass potential of sewage gas of village $x$ (GJ/year); $S_{x}$ is the amount of sewage sludge treated in rural sewage of village $x$ (tonnes/year); OM is the organic dry matter of sewage sludge in rural sewage plants (percent); GY is the gas yield $\left(\mathrm{m}^{3} / \mathrm{kg}\right.$ organic dry matter GEC is energy content of gas produced $\left(\mathrm{GJ} / \mathrm{m}^{3}\right)$.

When estimation of the HHV residual biomass magnitude was completed, the obtained information from evaluating the rural residual biomass using ArcGIS 10.3 was georeferenced and prepared as the layers of various sources (five layers including the residual biomass resources' 


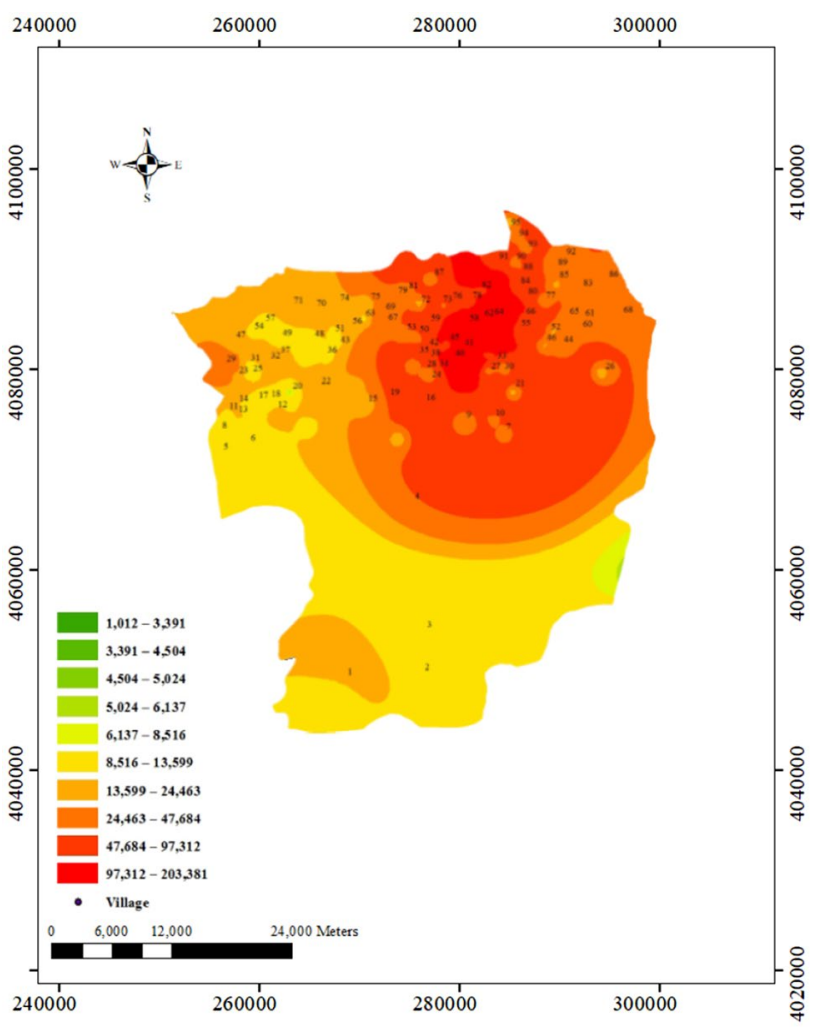

Fig. 6 Total amount of rural waste (GJ/year)

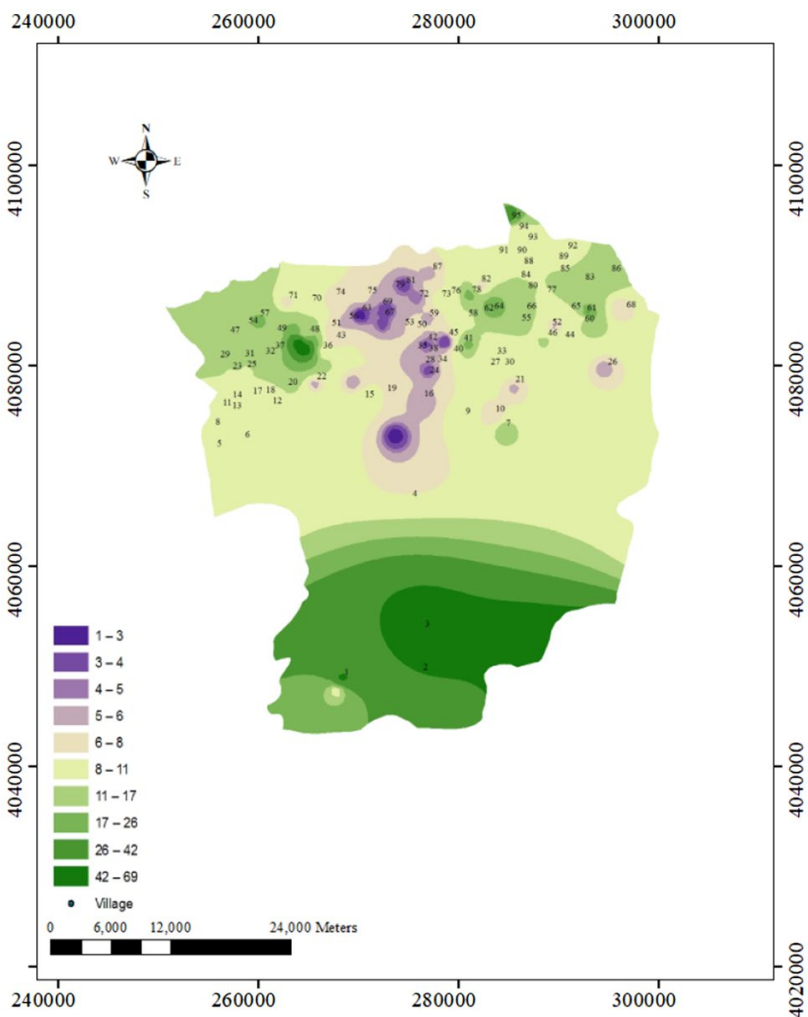

Fig. 7 Amount of rural waste per person (GJ/year/people)

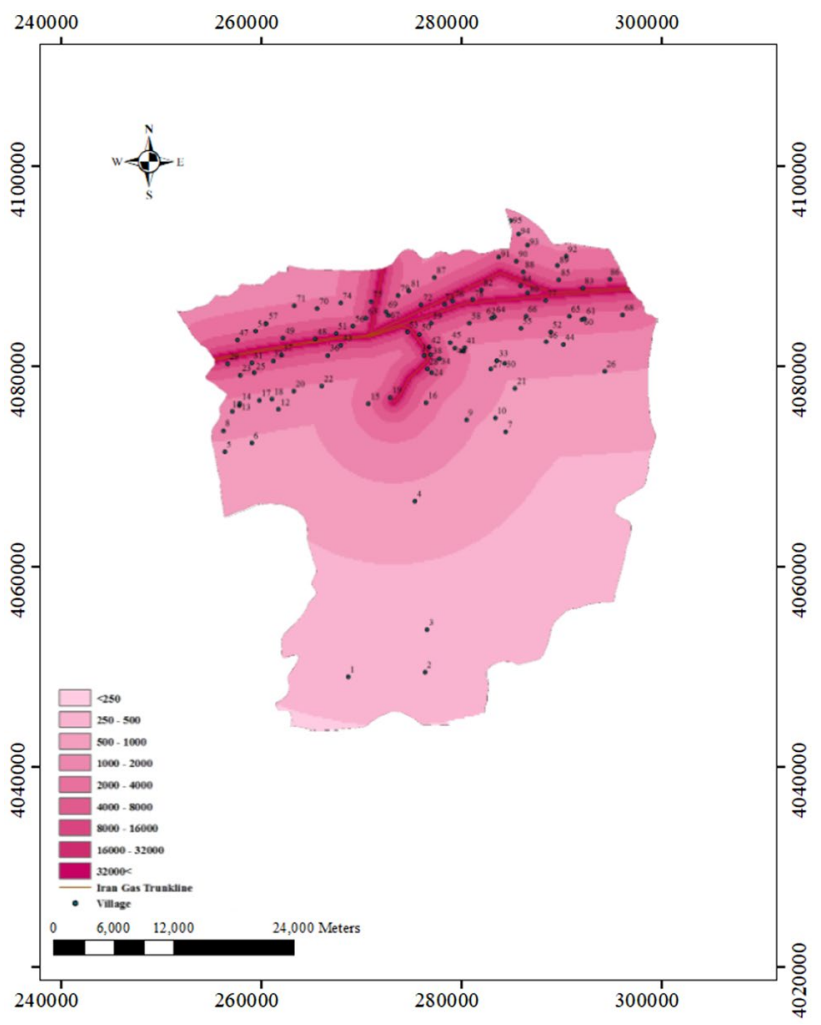

Fig. 8 Zoning of gas pipeline $(\mathrm{m})$

potential and population layer). Interpolation inverse distance weighting (IDW) was used based on the root mean square and calculated errors. The potential residual biomass production per capita and total $\mathrm{HHV}$ value per village were extracted in GIS for each village according to the rural population. Finally, a layer was created for the national gas transmission pipeline accessibility. The accessibility to natural gas and distance from the major energy carrier are reversely related. The residual biomass potentiometric map was created by considering the weight of accessibility to resource of the layers and the residual biomass information layers overlap in the GIS, and bioenergy development potential using the residual biomass resources was determined for each village, as shown in Fig. 5.

\section{Determining the accessibility coefficient by FAHP analysis}

The experts used the pair-wise comparison matrix to score the factors which were used for determination of the biowaste resources accessibility coefficients. The comparison results matrix is given in Table 4 .

The experts evaluated the parameters and rated each waste source regarding its accessibility importance. After 
Fig. 9 Total amount of rural waste and zoning of gas pipeline $(\mathrm{GJ} /$ year $/ \mathrm{m})$

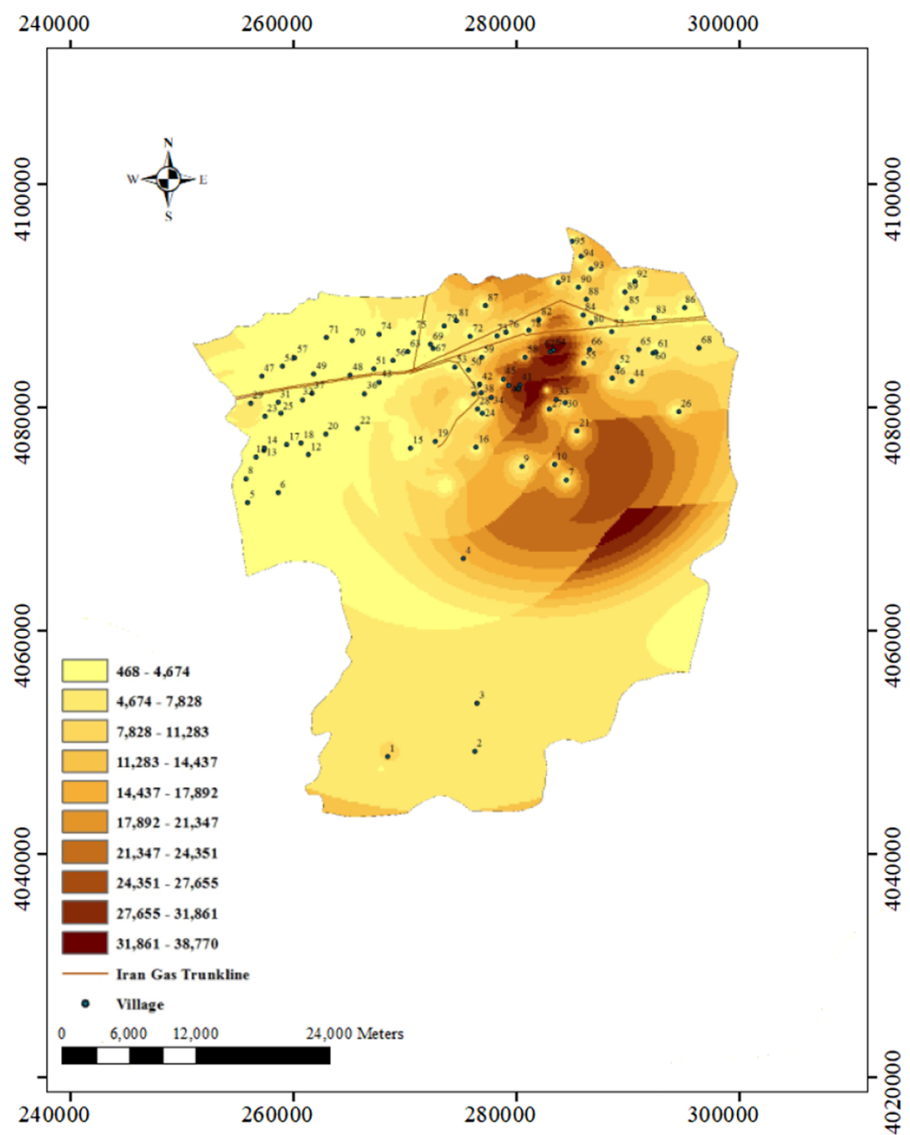

An estimation of the volume of the rural waste per person that is calculated by summing the total rural waste layer (Fig. 6) and the population density layer (Fig. 2) is shown in Fig. 7. The amount of available wastes for energy production for any geographical location regarding the rural population distribution is presented in this map. As it can be seen, the highest values correspond to the northwest and southern regions, while the lowest values correspond to the northern and central regions.

In addition, to determine the rural residential areas' accessibility to the natural gas carriers, the gas pipeline transmission plan was prepared and zoned based on the distance between the natural gas carrier and the areas. It was done in terms of the gas supply cost per person in the region. It is said by the experts that the lowest and highest costs of gas supply were for less than $250 \mathrm{~m}$ and more than $32,000 \mathrm{~m}$ from the major pipeline per person living in the area, respectively (Fig. 8). As it can be seen, in this region, the rural accessibility to the major energy carrier is reversely proportional to the factor of distance; as the area is farther, its accessibility is lower.

The new layer (Fig. 9) which shows the availability of energy per distance from the major pipeline is obtained by integrating the gas pipeline accessibility layer (Fig. 8) and the total rural waste layer (Fig. 6). 


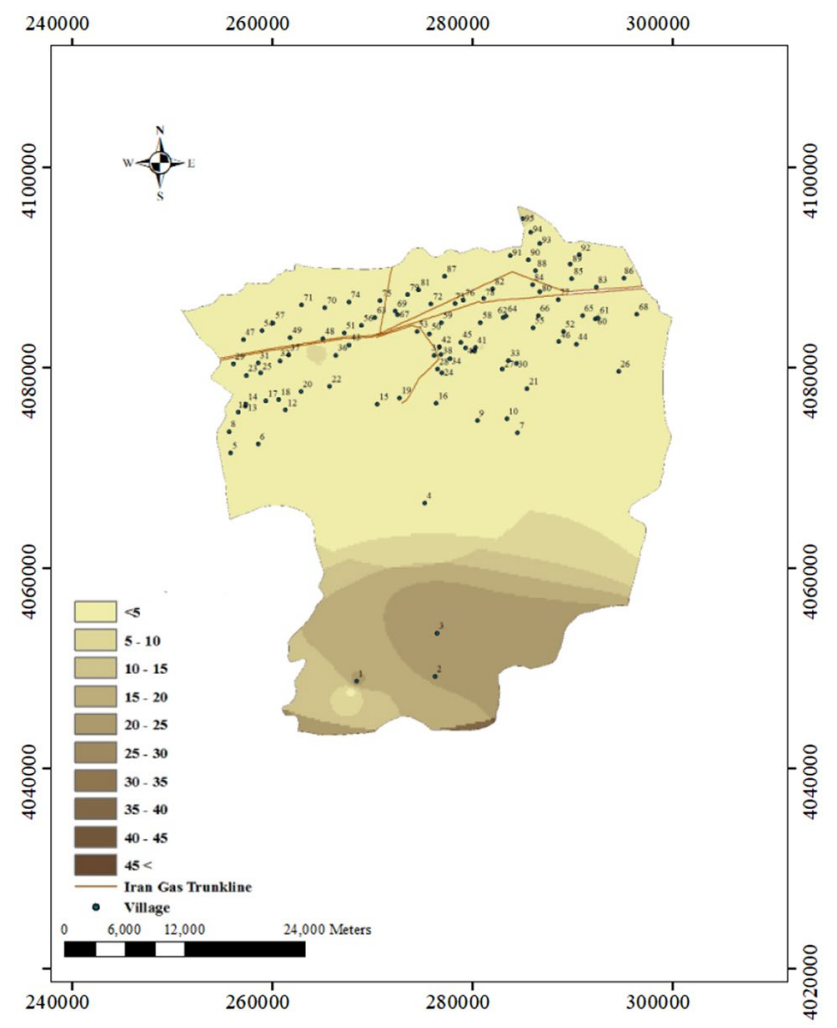

Fig. 10 Amount of rural waste per person and zoning of gas pipeline (GJ/year/people/m)

The new layer shown in Fig. 10 is obtained by merging the three layers of population dispersion (Fig. 2), the gas transmission line accessibility (Fig. 8) and the total rural residual biomass layer (Fig. 6).

\section{Conclusion}

The HHV of biomass resources and accessibility coefficients were used to quantify the residual biomass from agricultural and rural biowastes, and the potential extractable energy form the residual biomass resources, including wastewater, rural waste, livestock, horticulture wastes, farm wastes and poultry, was estimated. It was obtained that in 95 village of the region, a total amount of $1,191,022 \mathrm{GJ}$ energy per year can be produced. The largest amount corresponds to the agricultural biowaste resources $(987,986 \mathrm{GJ})$. The horticulture wastes and livestock waste have the potential of producing 94,416 GJ and $77,201 \mathrm{GJ}$ energy, respectively. This amount was $18,712 \mathrm{GJ}$ and $12,707 \mathrm{GJ}$ for the rural sewage and rural waste, respectively. Compared to the whole region, the eastern villages have a better status for energy extraction from the biomass resources due to their access to the gas pipeline $(40,41,58,64,65)$ and the estimated values of waste (Fig. 7). The density population and dispersion layer were not considered in the present study. The condition of each area can be analyzed using Fig. 8, the rural biowaste accessibility of each person and the distance from the gas transmission line. As it can be seen, the southern regions consist of three villages in the positions \#1, \#2 and \#3 and have a better chance of using the energy generating plans for providing the residential energy form the rural waste resources to the villages.

The total population of three villages in the region is 3772 people. Since these areas are located in high altitudes (2000 AMSL), they have low temperature, especially in winters. The severe winter weather forces a part of population to leave the area during the cold season. Mountain and forest roads are the only ways to access these villages which makes fuel transportation to these areas very difficult. Hence, using the waste resources to produce energy is so beneficial in the region and is an appropriate solution for the problem of these villages' accessibility to energy.

\section{Compliance with ethical standards}

Conflict of interest The authors declare that they have no conflict of interest.

\section{References}

1. Gregg J, Smith S (2010) Global and regional potential for bioenergy from agricultural and forestry residue biomass. Mitig Adapt Strateg Glob Change. https://doi.org/10.1007/s1102 7-010-9215-4

2. Almasi M, Bakhoda H, Emami M (2012) Principles and technology of organic waste utilization. Islamic Azad University, Tehran

3. Paiano A, Lagioia G (2016) Energy potential from residual biomass towards meeting the EU renewable energy and climate targets The Italian case,". Energy Policy 10(161-173):2016. https ://doi.org/10.1016/j.enpol.2015.12.039

4. Ahmadi K, Gholizadeh $\mathrm{H}$, Ebadzadeh $\mathrm{H}$, Hoseinpur R, Hatami F, Fazli B, Kazemain A, Rafiei M (2018) Agricultural Statistics. Ministry of Agriculture of Iran, Tehran

5. Iran Statistical Yearbook 1397, Deputy for Affairs, Statistics and Economical Infrmation Center, Tehran, Iran, 2018

6. Golestan (Iran: Province) Statistics Yearbook 1397, Programm and Budget Organization, Management and Planning Organization of Golestan Province, Iran, 2018

7. Babbie E (2002) The basics of social research, 4th edn. Wadsworth Thomson Learning, Belmont

8. Chen S, Hwang C (1992) Fuzzy multiple attribute decision making, methods and applications. Springer, Berlin. https://doi. org/10.1007/978-3-642-46768-4_5

9. Saaty TL (1990) Decision making for leaders: the analytic hierarchy process for decisions in a complex world. University of Pittsburgh, Pittsburgh

10. WASS, Washington agricultural statistics service, The 2004 Washington Annual Bulletin, Washington, USA (2004)

11. WASS, Washington Agricultural Statistics Service. The 2004 Grape Report, Washington, USA (2004) 
12. WSUCEEP, Washington State University cooperative extension energy program, wheat straw for ethanol production in Washington: a resource, technical, and economic assessment, Washington (2001)

13. Frear C, Zhao B, Fu G, Richardson M, Chen S (2005) Biomass inventory and bioenergy assessment. Department of Biological Systems Engineering Washington State University, Washington
14. Vis M, Van den Berg D (2010) Harmonization of biomass resource assessments. Best Practices and Methods Handbook, Freiburg

Publisher's Note Springer Nature remains neutral with regard to jurisdictional claims in published maps and institutional affiliations. 